\title{
A IMAGEM FOTOGRÁFICA NA ARTE BRASILEIRA: COLEÇÃO GILBERTO CHATEAUBRIAND UM ESTUDO DE CASO
}

Vanessa Biazioli Siqueira ${ }^{1}$

\section{Resumo}

O objetivo da presente pesquisa é detectar e refletir sobre a presença da imagem fotográfica na produção artística brasileira do início do século XX até a década de 1980, tendo como parâmetro a Coleção Gilberto Chateaubriand. Trata-se da Coleção de maior representatividade frente à arte brasileira dos séculos XX e XXI, reunindo de modo abrangente e significativo diferentes momentos dos anos de 1910 aos dias atuais. Desde 1993, encontra-se cedida, em regime de comodato, ao Museu de Arte Moderna do Rio de Janeiro (MAM-RJ). Reconhecida a presença da imagem fotográfica na arte brasileira, sobretudo na pintura, desde antes do advento do modernismo em 1922; faz-se necessário um estudo que trate do mapeamento da influência da imagem fotográfica na produção artística nacional.É nesse sentido que esta dissertação tem sua importância, tomando como base as obras da coleção Gilberto Chateaubriand do início do século XX até 1981.

Palavras-chave: fotografia, influência, coleção.

\begin{abstract}
The aim of this study is to detect and reflect about the presence of the photographic image in the Brazilian Art of the early $20^{\text {th }}$ century until the 80 's, having as reference Gilberto Chateaubriand's collection. This collection has been the most representative one among the Brazilian work of art since 1910. It has been conceeded since 1993 to the Modern Art Museum of Rio de Janeiro (MAM-RJ). Once acknowledge the presence of the photographic image, specialy in painting, since before the advent of Modernism in 1922, it's important to map the photographic influence in painting in the National Art work. Therefore this study is meaningful because it tends to investigate and point out this aspect in Gilberto Chateaubriand's painting collection from the beginning of the $20^{\text {th }}$ century up to 1981 .
\end{abstract}

Key word: photograph, influence, collection.

A pesquisa em história da arte no Brasil ainda requer muito trabalho; quanto ao levantamento para essa dissertação, sobre a presença da imagem fotográfica nas artes plásticas brasileiras, principalmente na pintura, percebeu-se grande dificuldade na obtenção de material bibliográfico a respeito do tema.

Outra escassez são as pesquisas relacionadas ao colecionismo no Brasil. Sobre a Coleção Gilberto Chateaubriand muitas informações ainda estão longe de serem conclusivas e sendo esta Coleção a fonte concreta a ser analisada, estudos anteriores e aprofundados sobre as singularidades da mesma poderiam ter contribuído em muito ao enriquecimento desse trabalho.

\footnotetext{
1 Mestranda pelo Departamento de Artes Plásticas da Escola de Comunicações e Artes (ECA) da Universidade de São Paulo (USP), sob orientação do Prof. Dr. Tadeu Chiarelli. Bacharel em História pela Faculdade de História, Direito e Serviço Social da Universidade Estadual Paulista (Unesp) - Campus de Franca, 1997, é membro do Centro de Pesquisa de Arte e Fotografia (CPArte\&Foto) também sob orientação do Prof. Dr. Tadeu Chiarelli.
} 
Tendo em vista que o foco dessa pesquisa recai, especificamente, sobre a arte brasileira, a escolha da Coleção Gilberto Chateaubriand justifica-se em primeiro lugar pelo fato de ser considerada, do ponto de vista quantitativo, a maior coleção de arte brasileira existente, pertencente a um único colecionador, contendo aproximadamente seis mil obras. Em segundo lugar é importante reforçar que, a Coleção Gilberto Chateaubriand contempla em seu interior a grande maioria dos artistas brasileiros - modernos e contemporâneos que alcançaram efetivo reconhecimento público em instâncias consagradoras oficiais (salões, bienais etc.).

Em relação a orientação metodológica analítica, essa tem por objetivo abalizar-se no estudo histórico comparativo entre as obras e as técnicas empregadas; sua relevância principal, reside na proficiência de estudos a esse respeito, já que a gama de possibilidades de uso da imagem fotográfica na produção artística como um todo é praticamente ilimitada.

Quanto à amplitude do período histórico determinado para a pesquisa - 1910 a 1981 - este assim foi constituído em função da própria Coleção, pois, suas obras mais antigas datam da década de 1910 e foi justamente no início da década de 1980, mais precisamente em 1981, após grande exposição realizada sobre a Coleção no Museu de Arte Moderna do Rio de Janeiro (MAM-RJ), que a Coleção passou a alcançar uma visibilidade nacional e até mesmo internacional, sendo aos poucos entendida como a melhor síntese da arte brasileira do século XX.

Iniciada em 1953 graças a um presente - um óleo sobre tela de nome Paisagem de Itapoã, dado pelo pintor José Pancetti ao então diplomata Gilberto Chateaubriand em viagem à cidade de Salvador - só viria se tornar uma coleção de fato, durante os anos de 1960, pois é quando Gilberto Chateaubriand exonera-se do cargo de diplomata brasileiro na França para vir cuidar no Brasil, dentre outras coisas, dos trâmites legais referentes ao inventário da herança deixada por seu pai Assis Chateaubriand. Hoje a Coleção encontra-se em regime de comodato (desde 1993) nos espaços do Museu de Arte Moderna do Rio de Janeiro (MAM-RJ) e continua sendo ampliada pelo colecionador, graças à constantes aquisições de novas peças.

Nesse momento, reiterando que o foco dessa pesquisa incidi sobre a arte brasileira, isto é, precisamente sobre a presença da imagem fotográfica na pintura brasileira entre 1910 a 1981 contida na Coleção G. Chateaubriand, faz-se necessária uma breve apresentação da história da fotografia.

Desde que a fotografia foi apresentada publicamente na França em 1839, por Louis Jacques Mandé Daguerre, esta passou a interpenetrar-se cada vez mais com as diversas artes e seus suportes, sobretudo na pintura, na medida em que se popularizou num mundo cada vez mais cosmopolita; sabe-se que artistas como Delacroix se utilizavam da fotografia para o estudo de seus modelos, o artista chegou a ter um álbum que, desde 1899 está na Bibliothèque National em Paris.

Os impressionistas também se inspiravam nas fotografias de multidões em movimento para construir seus quadros, principalmente Monet. ${ }^{2}$ Muitos pintores do século XIX se baseavam em fotografias para produzir suas telas, mas, escondiam ou destruíam as fotos por receio de serem taxados de maus pintores e, por conseguinte, durante um longo período essa prática foi mantida em segredo, principalmente porque a fotografia não era reconhecida como arte ${ }^{3}$.

\footnotetext{
2 SCHARF, Aaron. Arte y fotografia. Trad. Jesús de Santayana. Madrid: Alianza editorial, 1994.

3 TARASANTCHI, Ruth Sprung. Pintores paisagistas em São Paulo (1890-1920). São Paulo, 1986. Tese (Doutorado) ECA/USP.
} 
No Brasil, ao contrário da Europa, não há registros substanciais, alusivos ao uso da fotografia por artistas plásticos. Tal acontecimento talvez se explique pelo fato de que, para muitos desses artistas esta situação causava constrangimento. A fotografia também não chegou a ser reconhecida publicamente como uma "técnica auxiliar" da pintura, apesar de alguns exemplos célebres, como o do pintor acadêmico Pedro Américo que confessa em documento redigido a respeito do quadro que terminou em 1888, sobre a Independência do Brasil, ter feito uso em seus estudos e esboços preliminares "de algumas fotografias policromadas" onde apareciam condecorações e medalhas da época da independência. ${ }^{4}$

Durante o modernismo brasileiro, seja como atividade autônoma ou como elemento estruturador da pintura, a fotografia desfrutou de pouquíssimo destaque. Apesar de exceções como Tarsila do Amaral, Lasar Segall ${ }^{5}$ e Vicente do Rego Monteiro, segundo alguns estudos que apontam para o uso da fotografia na produção de determinadas obras desses artistas, é apenas Ismael Nery que, dentro do movimento, dedicou interesse especial à fotografia.

Um de seus trabalhos, Mão de Ismael Nery, sem data, constitui-se numa folha de papel preparada com sais de ferro, onde o artista pousou a mão e a expôs à luz. Enquanto durava a exposição, realizou alguns movimentos. Terminado o processo, Nery colocou o papel sob a água e viu surgir no lugar do cinza de onde se projetava a imagem da mão, um fundo de azul intenso. Nas extremidades da mão, o sinal de movimento era conferido pelos tons mais claro de azul. Essa foto por contato foi colada sobre uma folha de papel e, sob a imagem, ele escreveu a seguinte legenda:

A mão que fez os desenhos. Cópia em papel prussiato. Mas seu interesse não se restringe apenas ao fato de ser um tipo muito singular de auto-retrato. Mão de Ismael Nery pode ser pensada igualmente como cinema; cinema possível de ser produzido fixando precariamente o deslocar da mão sobre o papel durante a pose $^{6}$.

O intelectual modernista Mário de Andrade também teve um grande interesse pela fotografia e pelo cinema. Em seus arquivos, localizados no Instituto de Estudos Brasileiro da Universidade de São Paulo (IEB-USP), encontram-se inúmeras revistas especializadas sobre os temas e muitos retratos que produziu em suas viagens pelo Brasil nos anos de 1920 a 1930, mas só vieram a público nos anos de 1970, muito tempo depois de seu falecimento, não tendo nenhuma ressonância pública na época de sua execução.

A fotografia como elemento significativo na constituição da produção visual do país ganharia maior visibilidade no final dos anos de 1950, início dos de 1960. Sua difusão fará com que antigas práticas sejam reavivadas e que novas possibilidades de inserção no quadro das artes visuais sejam criadas.

Observando aquele período, nota-se trabalhos onde a fotografia sofre a transferência direta para a tela ou para outros suportes bidimensionais, por meio da

\footnotetext{
${ }^{4}$ MELO, Pedro Américo Figueiredo e. O Brado do Ipiranga ou Proclamação da Independência do Brasil. Algumas palavras acerca do fato histórico e do quadro que o comemora. Florença: Tipografia da Arte della Stampa, 1888.

5 Lasar Segall na tela Encontro utiliza-se da fotografia para incluir-se na pintura. Sobre o assunto ver: CAMARGO, Mônica Junqueira de e MENDES, Ricardo. Fotografia: cultura e fotografia paulista no século XX. São Paulo: Secretaria Municipal de Cultura, 1992.

${ }^{6}$ CHIARELLI, Tadeu. Quando a fotografia se torna arte?: um panorama do uso da fotografia por artistas brasileiros. São Paulo, 2005, p.11. (Texto inédito)
} 
colagem, mesclada a procedimentos gráficos ou pictóricos: as chamadas assemblagens. O primeiro representante dessa construção é o norte-americano Robert Rauschemberg que trabalhava com a tela como uma prancha plana, as combine paintings. ${ }^{7}$ No contexto brasileiro, alguns artistas vão dialogar com esse tipo de trabalho, os primeiros são Wesley Duke Lee e Nelson Leirner, propondo uma simultaneidade de visualidades de origens distintas, numa mesma peça.

As produções desses dois artistas constatavam pioneiramente uma nova cena brasileira: multifacetada, polissêmica e, portanto, impermeável a qualquer composição unificadora. Mesclando índices das culturas visuais "alta" (pintura) e "baixa" (a imagem fotográfica), refletiam sobre a cena social/urbana brasileira que se tornava ainda mais complexa naquele período e que até então estivera fora das preocupações dos artistas locais, a não ser como projeção utópica (as tendências construtivas que os antecederam).

Concomitante ou um pouco posteriores a essas produções, nota-se o ressurgimento da fotografia como "importante auxiliar" da pintura, tanto nas obras que dialogavam com a realidade bruta da história local e internacional, quanto àquela que buscava reorganizar a potencialidade alegórica do meio pictórico, por meio da imagem fotográfica.

No primeiro caso, são importantes as pinturas produzidas por Claudio Tozzi pertencente a uma segunda geração de artistas brasileiros ligados à retomada figurativa no paralelo com a pop-art da segunda metade da década de 1960. Da aproximação maior inicial com os americanos da pop (Roy Lichenstein, por exemplo) - muitas vezes entendidas como uma interpretação às vezes ingênua de matrizes apropriadas - seus desenhos, pinturas e gravuras, no entanto, apresentam uma complexidade maior, apontando para uma rearticulação de fontes que incluem também a cartazística cubana e soviética.

No segundo caso, Glauco Rodrigues desenvolverá uma pintura onde também o uso da imagem fotográfica não será ocultado, pelo contrário. Em suas produções, as imagens vindas da fotografia (ou de pinturas históricas reproduzidas via esse meio), reformularão emblemas da cultura brasileira. No entanto, o caráter solene que sempre distinguiu as pinturas alegóricas será descaracterizado pela informalidade e ironia da imagem fotográfica que terá suas qualidades transferidas para as pinturas de Rodrigues.

Por mais diferentes que sejam esses artistas e por mais distintos que sejam suas propostas de uso de imagem fotográfica, atente-se para um fato: não operam mais com o conceito de artista criador de formas originais que ordenam o mundo. Cada um à sua maneira, e mesmo fazendo uso de meios tradicionais (como a pintura), justamente por trabalharem com a fotografia ou com a imagem fotográfica, desestruturam na prática $\mathrm{O}$ próprio conceito de artista de vanguarda, aquele preocupado com o novo, com o devir.

Se os artistas comentados acima, mesmo trabalhando com a apropriação de fotografias e/ou de imagens fotográficas, podem ser alinhados com a arte tradicional, os que serão comentados a seguir podem ser unidos por incorporarem nos trabalhos elementos possuidores de uma "lógica fotográfica" conectada aos usos que ela assumiu desde seu aparecimento.

Anna Bella Geiger, durante os anos de 1970 desenvolverá uma série de trabalhos envolvendo sua condição de mulher, artista e de cidadã latino-americana. Em Da série Indagações sobre o Significado e Função da Obra de Arte, a artista, apropria-se da fotolinguagem, da cópia xérox e do vídeo, visando o questionamento do sistema das artes, indagando sobre suas estruturas e procedimentos.

${ }^{7}$ CRIMP, Douglas. Sobre as ruinas dos museus. São Paulo: Martins Fontes, 2005. 
Ainda no contexto dos anos de 1960/1970, uma série de trabalhos ligados à performance e/ou às ações coletivas produzidas por artistas como Hélio Oiticica, Lygia Clark, Cildo Meireles e Iole de Freitas, entre outros, foram documentados fotograficamente.

No caso da última artista, é interessante que suas fotos extrapolavam o caráter puramente documental aspirando, em grande parte, tanto a uma dimensão estética e formal, quanto a uma dimensão narrativa, o que garante certo descolamento dessas imagens das performances que as possibilitaram Um exemplo bastante conhecido é a série Cacos de vidro, fatias de vida de 1975, o qual a artista apresenta pela primeira vez no Museu de Arte Contemporânea da USP. ${ }^{8}$

Como se pode perceber, a partir dos anos de 1960/1970 começa a se estabelecer no Brasil uma presença cada vez maior da fotografia e da imagem fotográfica no âmbito da produção artística mais contundente que aqui se realiza. Essa presença, ao mesmo tempo em que reflete uma situação internacional análoga, amplia a complexidade da cena artística local. A fotografia como elemento estruturador de uma parte significativa da arte brasileira, não deve ser vista apenas como uma "curiosidade", ou como um aspecto menos importante da arte que aqui se realiza nas últimas décadas. Ela deve ser estudada em pé de igualdade tanto com as vertentes que tentavam dar prosseguimento às indagações plástico/formais do modernismo internacional, quanto pela exploração das potencialidades do corpo individual e coletivo, que visavam romper com os estatutos do modernismo.

Afinal, o uso da fotografia e da imagem fotográfica - como já foi evidenciado -, não se restringiu aos seus aspectos apenas auxiliares. Cerne do raciocínio visual de muitos artistas, a fotografia também serviu como porta de entrada para que certos componentes ligados pela tradição a outras modalidades artísticas (como a literatura e o próprio cinema) ingressarem no campo das artes visuais de forma plena, problematizando conceitos tradicionais que separavam as artes do "tempo" e as artes do "espaço", conceitos esses reiterados pelo modernismo internacional.

Como foi mencionado, em paralelo ao interesse de vários artistas plásticos pela fotografia, assiste-se à fotografia tradicional desvincular-se de seus compromissos com o referente, buscando uma autonomia artística, até então percebida apenas em alguns centros internacionais. A essa reivindicação correspondeu uma presença cada vez maior, a partir dos anos de 1970, no Brasil, da fotografia convencional em museus de arte e galerias.

Foi quando começaram a sobressair as produções de artistas como Miguel Rio Branco e outros. O que caracterizaria, a capacidade de mesclarem a um interesse pelo referente, olhares diferenciados, desenvolvidos a partir da absorção (sempre seletiva) das várias vertentes da fotografia moderna internacional.

No Brasil a produção mais articulada entre fotografia e outras modalidades artísticas, não se extinguiu no final dos anos de 1970 para ressurgir no final da década seguinte. De maneira menos sistemática, talvez, ou, quem sabe, de forma mais subterrânea, novos artistas, dariam prosseguimento a propostas de hibridação entre a fotografia e outros mídias, mesmo quando, na corrente principal da arte brasileira da primeira metade dos anos de 1980, só se falasse sobre a "volta à pintura".

De maneira geral, a produção desses jovens artistas "híbridos" discutia, em primeiro lugar, a banalização das imagens fotográficas no mundo contemporâneo. Contra

${ }^{8}$ CAMARGO, M. J. de e MENDES, R. Op. cit. 
esse fato propunha ressignificar tais imagens por meio da apropriação e manipulação das mesmas, trabalhadas, sobretudo como elementos constitutivos de objetos tridimensionais.

Talvez, entre o final dos anos de 1980 e a primeira metade da década seguinte, o Brasil tenha vivido o primeiro momento culminante dessa arte híbrida, que mescla à fotografia elementos objetuais e espaços-temporais. Não que anteriormente não tenha sido possível perceber contribuições importantes neste sentido. Porém, até aquele momento, embora já bastante presente, não era possível perceber a produção artística contaminada pela fotografia como uma verdadeira tendência. É a partir do final dos anos de 1980, e motivada por obras repletas de potência, produzidas não apenas por então jovens artistas, mas também por aqueles mais velhos, que continuaram se manifestando por esse viés de hibridação, que a fotografia, em suas novas relações com os outros meios, ganha maturidade no país.

A fotografia brasileira mais recente, apesar da riqueza dessa produção apenas arrolada nos parágrafos acima, não está se transformando e se desenvolvendo apenas nos desvãos entre as linguagens, a partir de narrativas ou poemas visuais que tendem a se desdobrar no tempo real. Uma vertente que, um tanto subterrânea, resiste e se transforma na atualidade, é a fotografia que sugere ter sido realizada para documentação de performances ou intervenções urbanas. No entanto, quase sempre a motivação é contrária: as intervenções e as performances são feitas justamente para resultarem fotografias.

Pelo que foi aqui demonstrado, no geral, pensar arte e fotografia no Brasil é pensar praticamente sobre um único fenômeno, tendo em vista que, tanto a fotografia quanto a arte (esta última aqui entendida como manifestação erudita), se estabeleceram ao mesmo tempo no país. De maneira mais específica, no entanto, levando em consideração a produção dos últimos 50 anos, a arte estruturada pela fotografia constitui-se como uma manifestação fundamental da arte brasileira, espaço em que alcançou alguns de seus momentos mais intensos.

Apesar, no entanto, da fotografia se confundir com a própria arte erudita no Brasil e de ter sido responsável por algumas das produções artísticas mais relevantes, a história de suas relações complexas com as artes, como foi visto, ainda é lacunar, porque pouco explorada.

\section{Referência Bibliográfica: \\ Arte e fotografia}

ALPERS, Svetlana. A Arte de descrever: a arte Holandesa no século XVII. Trad. Antonio de Pádua Danesi. São Paulo: EDUSP, 1999.

ARGAN, Giulio Carlo. Arte Moderna. Trad. Denise Bottmann e Federico Carott. São Paulo: Companhia das Letras, 1999.

BENJAMIN, Walter. "A obra de arte na era de sua reprodutibilidade técnica". In: Magia e técnica, arte e política: Ensaios sobre literatura e história da cultura. (Obras escolhidas; v.1) São Paulo: Brasiliense, 1987.

BENJAMIN, Walter. "Pequena história da fotografia". In: Magia e técnica, arte e política: Ensaios sobre literatura e história da cultura. (Obras escolhidas; v.1) São Paulo: Brasiliense, 1985, p. 91-107.

BORGES, Maria Eliza Linhares. História \& Fotografia. Belo Horizonte: Autêntica, 2003. (Coleção História \&... Reflexões; v.4). 
CAMARGO, Mônica Junqueira de e MENDES, Ricardo. Fotografia: cultura e fotografia paulista no século XX. São Paulo: Secretaria Municipal de Cultura, 1992.

CHIARELLI, Tadeu (cur.). Apropriações/coleções. (catálogo de exposição). Porto Alegre: Santander Cultural, 2002.

- Quando a fotografia se torna arte?: um panorama do uso da fotografia por artistas brasileiros. São Paulo, 2005. (Texto inédito)

COSTA, Helouise e SILVA, Renato Rodrigues da. A fotografia moderna no Brasil. São Paulo: Cosac Naify, 2004.

CRIMP, Douglas. Sobre as ruinas dos museus. São Paulo: Martins Fontes, 2005.

FABRIS, Annateresa (org.). Fotografia: usos e funções no século XIX. São Paulo: EDUSP, 1991. (Coleção Texto \& Arte; v.3). "Uma outra história da arte?" [Trabalho apresentado em $A$ bistória da arte hoje. Seminário de pós-graduação do Dep. Artes Plásticas, ECA - USP, São Paulo, 16-19 maio 2000].

FREUND, Gisèle. La fotografía como documento social. Trad. Josep Elias. Barcelona: Editorial Gustavo Gili, 1976.

KOSINSKI, Dorothy (org.). El artista y la cámara: De Degas a Picasso. Trad. Itziar Elgezabal e Susana Fornies. Bilbao: Museo Guggenheim, 2000.

KOSSOY, Boris. Origens e expansão da fotografia no Brasil - século XIX. Rio de Janeiro, FUNARTE, 1980.

KRAUSS, Rosalind. O fotográfico. Trad. Anne Marie Davée. Barcelona: Editorial Gustavo Gili, 2002.

MELLO, Maria Teresa Villela Bandeira de. Arte e fotografia: o movimento pictorialista no Brasil. Rio de Janeiro: FUNARTE, 1998.

MELO, Pedro Américo Figueiredo e. O Brado do Ipiranga ou Proclamação da Independência do Brasil. Algumas palavras acerca do fato histórico e do quadro que o comemora. Florença: Tipografia da Arte della Stampa, 1888.

MENEZES, Paulo Roberto Arruda de. A trama das imagens: manifestos e pinturas no começo do século XX. São Paulo: EDUSP, 1997. (Coleção Texto \& Arte; v.14)

SCHARF, Aaron. Arte y fotografía. Trad. Jesús Pardo de Santayana. Madrid: Alianza editorial, 1994.

SCHWARCZ, Lilia Moritz. As Barbas do imperador: D. Pedro II, um monarca nos trópicos. $2^{\mathrm{a}} \mathrm{ed}$. São Paulo: Companhia das Letras, 1998.

SONTAG, Susan. Ensaios sobre a fotografia. Rio de Janeiro: Arbor, 1981

STELZER, Otto. Arte y fotografía: contactos, influencias y efectos. Trad. Michael Faber-Kaiser. Barcelona: Editorial Gustavo Gili, 1981.

TARASANTCHI, Ruth Sprung. Pintores paisagistas em São Paulo (1890-1920). São Paulo, 1986. Tese (Doutorado) ECA/USP.

TEIXEIRA COELHO (org.). A Modernidade de Baudelaire - textos inéditos. Rio de Janeiro: Paz e Terra, 1988. 